\title{
THE ELOQUENCE OF THE PHOTOGRAPHIC IMAGE IN THE DESIGNS OF POSTERS OF HUMANITARIAN ORGANIZATIONS (POSTERS OF DISPLACED IRAQIS AS A MODEL)
}

\author{
Lina Emad FATHY*
}

College of Fine Arts, University of Baghdad, Iraq

\begin{abstract}
The true photographic image is conveyed through a brief image and summarizes measurements, volumes and events, and the print designer employs it through pictorial angles of vision that intensify the dialogue and convey it eloquently and simulate it at times and metaphor at times. The image in the typographic design has intentionality that stems from the ideological references of the designer, making the photographic image the signifier and the signified and the relationships that bind them together, the current research includes two chapters, the first chapter is the research problem and the need for it, and the importance of the current research is in the exit of the photographic image from being less realistic to its subjection The duality of assignment and inclusion, the duality of substitution and composition, the duality of signifier and the signified, the duality of simultaneity and succession, as well as the use of the image in a very important topic, namely the human posters related to forced displacement.

Keywords

The Eloquence, The Photographic, Image, Designs, Posters, Humanitarian Organizations.
\end{abstract}

\section{Introduction}

The researchers set out to define the research problem by answering the following question: What is the rhetorical effect of the image Photographic in the recipient posters of humanitarian organizations? While the current research is defined by topics of eloquence of photographic images of humanitarian organizations related to Iraqi immigrants and temporally from 20142017, the second chapter of the research includes two topics: the first examines forced displacement and posters of humanitarian organizations, while the second searches for the rhetoric of the photographic image in the poster, and the research reached results, the most important of which are:

1. The real image is the image of the analogy, while the rhetorical image in the poster is easy to receive for use as metaphors based on pre-agreed relationships, and it is a message from the typographer to the recipient who makes the interpretation according to his references.

2. The inherited symbols, metaphors and similes in the poster do not come out of being enhancers that slip from the hands of rhetoric into a picture.

3. The picture in the poster deviates from the visual form framing, to the visual relations and the visual dialogue, that the photographic image in the poster is that visual scenic image that the recipient imagines mentally and physically. The photographic image greatly affects the transmission of human suffering in general and those who have been subjected to forced

* Corresponding author: web.admin@ cofarts.uobaghdad.edu.iq 
displacement in particular

\section{Research problem:}

The two researchers set out to define the research problem by answering the following question: What is the rhetorical effect of the photograph on the recipient of the posters of humanitarian organizations?

\section{Forced displacement:}

International law prohibits clear rules against forced population displacement, as it stipulates a set of prohibitions concerned with addressing the main drivers behind the displacement of people from their homes, including limiting attacks targeting the civilian population and illtreatment, and humanitarian relief materials should be provided and facilitate their access to those Those who need it, under the provisions of Article (49) of the Fourth Geneva Convention, which prohibits the collective or individual forcible transfer of protected persons, whatever the motive. The crime of forced displacement includes the following elements:

1 - The occurrence of acts or omissions that lead to the forcible transfer of civilians from their places of residence, or from the area in which they are lawfully located, to a place outside that region.

2- Harming these acts or negligence on protected persons.

3- The population transfer will not be to meet the security needs of the population concerned, nor does it represent a compelling military necessity.

International human rights law guarantees a myriad of established human rights protections, which are stipulated in major legal instruments, and which have direct and indirect impacts on the issue of preventing displacement. The most important of these are protection of the right to life, the right to health care, the right to food, the right to adequate housing, the right to be free from discrimination and the right to development.

The problem of the displaced grew in the 1960s, as it recorded five million displaced people, compared to nine million refugees in the 1950s, and this preparation increased after the Cold War and the increase in armed conflicts in the countries, which led these factors to a dramatic increase in the number of displaced persons, until it reached about twenty to twenty five million displaced persons as a result For these conflicts, knowing that the most prevalent conflicts today are those that are characterized by a non-international character, and from the characteristics that the conflict is non-international between people who know the political and economic background, social organization, culture and customs of each other, as people leave their home and move to another place due to tensions, conflicts or persecution, except They differ in the spatial aspect, i.e. the point of arrival. An internally displaced person moves within 
the framework of a single state. As for the refugee, he moves from the borders of his country to another state, which requires that the refugee enjoy a legal system other than that established for the internally displaced, because the latter, as we explained earlier, exercises citizenship rights within the state, which has changed My location and not a change in legal status, unlike a refugee whose legal status changes in the country of asylum.

\section{Photo, photography and digital photography:}

The image, in its general concept, emerges from a representation of the visual reality mentally or visually, or a direct perception of the objective external world as an embodiment, sensation and vision, and on the one hand, this representation is characterized by condensation, reduction, abbreviation, miniaturization, imagination and transformation. On the other hand, it is characterized by exaggeration, exaggeration, exaggeration and exaggeration. And then, the relationship of the image to the representative reality is a direct simulation relationship, or a dialectical reflection relationship, or a relationship of analogy, or a blatant paradox relationship. The picture is of a linguistic nature at times, and visible at other times. In other words, the image is verbal, linguistic, and dialogical, and a visual image is non-verbal.

The image is of great importance in conveying the objective world, holistically, concisely and concisely, and condensed it into a few visual units. Confucius, the Chinese sage, said: "A picture is better than a thousand words."

Photography or the art of light painting, as the name 'photography' comes from the Greek word photograph, which is divided into two words: Photo, which means light. Graph, which means drawing or writing, as when the photographer takes a specific image, he simply fixes the movement of things in a specific time and place, and it is an art of fine art that is independent from the rest of the other arts, and the photographic image is a brief picture of the real reality in size, size, angle, perspective and intensification And imagination and imagination.

The photographs are distinguished by their professional and technical nature, their artistic and aesthetic character, their symbolic and semantic nature, and their ideological and intentional nature. The photographic image consists of the iconic signs or the iconic dimension (faces, bodies, nature, animals. , .....) and the totality of direct and indirect intentions, defining the photographic vision of the world.

\section{Digital photo:}

The digital image is the computer image that exists within the spaces of the World Wide Web. This image is characterized by its technical, digital and virtual nature. Hence, it is a sophisticated, modern and functional image, linked to the computer and the digital network, and it is possible - now - to find all the desired images in it, without resorting to plastic or 
photographic, there are images that are abundant within the digital electronic worlds here and there, from which a person chooses what he wants.

More than this, many plastic, cinematic, theatrical, advertising and other pictures have been transformed into modern digital images, controlled by the computer by fixation, change or modification. All this means that the formation has benefited from the technological revolution in the field of investing in the digital image quickly, flexibly, easily, and conveniently for attachment, composition and creativity, and today, it is absolutely indispensable - at all - from the digital image Due to its technical importance, and its eloquent media and technological role, the digital image is symbolized by a two-dimensional matrix $\mathrm{f}(\mathrm{x}, \mathrm{y})$, and it often consists of small square pieces called elements (pixels), the locations of these elements in the matrix correspond to the locations of the original image points represented by the space coordinates $(\mathrm{x}, \mathrm{y})$ while the values of these elements are proportional to the value of the light intensity at those points, and the monochromatic image is represented by a single function ((one dimension) bits / pixel1) that contains brightness information only, and it is defined as a function of the intensity of the light arriving at the sensor (Visual system) As for lightness in scale images, in this type of image there is a reference to unicolor and includes brightness information, that is, it does not contain color gradients, and the value of each element in the image determines the gray scale that ranges between (0-209) or (1-0) in the case of standardization, and each of its components is represented by (bits / pixel^), and often it is represented by (bits / pixel-12) or (bits / pixel-16) such as medical imaging as well as pictures. The color represented by (24-bits / pixel) is called the Sow The true color is True Color and the number of colors in it is equal to $(19,777,190,224)$ colors. The color of the point in this image consists of a mixture of the three main colors RGB, and each color represents one byte1 or bits- 8 , and a single point represents by three bytes. This type of image is represented by three packets of monochrome data and each packet of these packets returns to luminosity In each of the primary colors, which are red, green, and blue, using (8-bit / pixel) in each light beam, and therefore the color image is represented by (24-bit / pixel).

\section{Photo montage and poster design:}

Photomontage technology must be used, which uses software as a basic element in the artwork. Today's print designer cannot be able to master the various software programs to produce his design product as required, if many different ideas that combine him with the modern sciences that are widespread in our modern era emerge from them. Mentioning the digital photo design process in a subjective artistic experiment. The emergence of photo montage technology has led to a change in the concept of creative work from manual and physical technology to the 
virtual dimension of visual perception, and from here the creative topics that adopt the process of vision varied.

Photo montage is summarized in the technique of collaging as a digital collage, where this practice is based on collecting parts of cropped images, rearranging them and installing them into a new digital image. The digital image is the birth of a new tool in know-how, and it differs from photographs in that they are hybrid images through a computer and a digital camera. Or at least supported by them, and draws their plastic value from their role as information, and they are dealt with and dealt with depending on the computer and digital software, including the Photoshop program, Corel Draw, and many modern programs that appear constantly.

\section{Rhetorical picture:}

The image has known through historical development multiple literary, artistic or poetic connotations. The Greek philosopher Aristotle used to see that the image is a metaphor based on the similarity and similarity between the two sides likened and likened to it, but he used to call the metaphor and metaphor an image ", and Homer says about Achilles: he starts off like a lion, This is an analogy, but when he says: The lion starts off, then this is a metaphor, and since both of them share the meaning of courage, the poet wanted by metaphor to call Achille a lion.

Thus the rhetorical or discursive image is based on simile and metaphor, and after the image was related to the generator of sense, reason and imagination, it moved with the surrealists to be associated with the unconscious and the unconscious imaginative, while for the semiotics it was associated with the semiotic component with the semiotics of action, and in the visual and digital semiotics it evolved to relate to the visual and iconic component, Rhetorical, literary and poetic studies have confined the artistic image to the relationship of analogy based on simile and metaphor, without relying on the relationship of neighborliness based on the sender metaphor and metaphor, which dominates literary and narrative prose.

The efficacy and impact of the rhetorical image is clearly evident for its simplicity on the one hand, and the ease of extracting and identifying it by the recipient on the other hand, the real image is the image of analogy, and in both cases, the displacement on which the sender is based is easily overridden and reduced, these metaphors are based on pre-prepared relationships It does not require effort, neither from the designer to create it, nor from the recipient in order to interpret it.

The image is a transformation of what is familiar and is used in a design language that is metaphorical, metaphor and rhetorical influencing what is returned, and then, the image is a process of transformation, change, substitution and replacement, since not every image is a 
displacement, and not every shift is an image, and this means that the concept of displacement is a concept that is short in understanding the image Rhetoric; Because there are some old rhetorical images that are not displacements.

\section{Conclusions:}

1. The real image is the image of the analogy, while the rhetorical image in the poster is easy to receive for use as metaphors based on pre-agreed relationships, and it is a message from the typographer to the recipient who makes the interpretation according to his references.

2. The image in the poster departs from the traditional meaning to achieve a formative dimension at times, and an iconic dimension that pushes the recipient to interpret once, and interpretations once, my brother, in clear meanings and others in the poster MUNARI, Bruno. Design and visual communication. Chronicle Books, 2006.

3. Photo montage techniques make a major contribution to bringing out the image in the poster and making it more effective on the recipient.

4. The inherited symbols, metaphors and similes that are used in the poster do not come out of being enhancers that slip away from the hands of rhetoric to become an image.

5. The method of exaggeration and the use of spacing between the elements of the image is a real way to attract the recipient.

6. The image in the poster deviates from the visual form framing, to the visual relations and the visual dialogue, as the photograph in the poster is that visual scene image that the recipient imagines mentally, sensory and motor.

7. The image achieves a fourth dimension through the movement represented by the time of the image and beyond, and it achieves with other design techniques the effect and the realization of the designer's forced goals.

8. The photographic image greatly affects the transmission of the suffering of humanity in general and those who have been displaced in particular.

\section{References:}

1. Ibn Manzoor, Lisan Al-Arab, article: (reached).

2. Aristotle: Rhetoric, translated by: Abd al-Qadir Qutini, East Africa, Casablanca, Morocco, first edition in $2008 \mathrm{AD}, \mathrm{p} .: 121$.

3. Al-Sakaky, Abu Ya`qub Yusef Ibn Abi Bakr Muhammad Ibn Ali Miftah al-Uloom, Lebanese Dar al-Kutub Beirut 18.

4. Kaddour, Abdullah Thani, Semiotics of the Image, Al-Warraq Foundation for Publishing and Distribution, Amman, Jordan, first edition, 2008 AD, p: 2-2.

5. Qaddour Abdullah Thani: Semiotics of the Image, Al-Warraq Foundation for Publishing and 
Distribution, Amman, Jordan, first edition in 2008, p: 4

6. Moussa Kazem Mohsen, and others, improving the digital image using quality standards. Babylon University Journal, College of Pure and Applied Sciences, Vol. 2, 2010.

7. MUNARI, Bruno. Design and visual communication. Chronicle Books, 2006 6. Building Accountability, Legitimacy, and Peace: Refugees, Internally Displaced Persons, and the Right to

8. International field protection of internally displaced persons, project is co-financed by the European initative Source w someowwe Molino-Joëlle Tamine: Introduction à l'analyse linguistique de la poésie, P.U.F.Paris, 1982.

9. Oswald Ducrot / Tzvetan Todorov: Dictionnaire encyclopédique des sciences du langage, Collection Points, éditions du Seuil. Paris, 1972.

10. http://www.isdonline.org/index.php?limitstart=60

11. http://www.isdonline.org/index.php?limitstart=60

12. http://www.isdonline.org/index.php?limitstart=60

13. http://www.nabeel.it/

14. http://www.uniraq.org/media/

15. http://www.unocha.org/iraq.

16. https://amymctighe.wordpress.com/tag/iraq/

17. https://ar.wikipedia.org/wiki/

18. https://designshack.net/articles/inspiration/10-tips-for-perfectposter

19. https://goo.gl/c1wvqR

20. https://goo.gl/RHGjBw

21. https://www.cis.rit.edu/htbooks/dtp/projects/poster/poster1.html

22. WwW.icrc.org

23. Nahla Ali BAKIR, STYLE OF PERFORMING THE FLUTE CONCERTO BY JOSEPH BOUDIN DE POMERTE (1755-1689) J.B.DE BOISMORTIER, International Journal of Humanities and Language Research, Vol. 2, No. 1, 2019, pp. 20-27.

Received: July 6, 2019

Accepted: September 21, 2019 